\title{
NITRATE IN GROUNDWATER AND ITS ASSOCIATED HEALTH RISK: A CROSS-SECTIONAL STUDY IN MUKIM SALOR, KOTA BHARU, KELANTAN, MALAYSIA
}

\author{
Che Mohamad Farizuan'), Shaharuddin'), Zaenal Abidin²) \\ ${ }^{1)}$ Department of Environmental and Occupational Health, \\ Faculty of Medicine and Health Sciences, \\ Universiti Putra Malaysia, 43400 UPM Serdang, Selangor, Malaysia \\ ${ }^{2)}$ School of Health Sciences Bhakti Husada Mulia, Madiun, East Java, Indonesia
}

\begin{abstract}
Background: Mukim Salor is an agricultural area in the district of Kota Bharu, Kelantan state, Malaysia. Farmers there use nitrogen-based fertilizers for paddy and vegetable planting. The use of these types of fertilizers may lead to contamination of nitrate in groundwater by the process of leaching into the soil. Kota Bharu is one of the areas in this country where the population still rely on groundwater as their main source of potable water. Daily use of water contaminated with nitrate may give rise to problems including "methemoglobaenamia" or blue baby syndrome and shortness of breath. At the moment, there are no data available on nitrate levels or hazard index associated with nitrate exposure in groundwater in Mukim Salor. This study aimed to determine nitrate levels in groundwater and to perform health risk assessment from nitrate exposure among residents in Mukim Salor, a subdistrict in the district of Kota Bharu, Kelantan, an east coast state in Peninsular Malaysia.
\end{abstract}

Subjects and Method: This cross-sectional study was conducted among residents from Mukim Salor, Kelantan, Malaysia. Fifty (50) respondents were chosen based on the inclusion and exclusion criteria and they were initially interviewed in order to obtain demographic data and groundwater usage information. Groundwater samples were taken from each of the respondent's house who used groundwater exclusively for drinking and cooking. The samples were then analyzed using a HACH brand DR 1900 direct reading spectrophotometer. Risk assessment on exposure to nitrate was also calculated.

Results: Nitrate levels ranged from 0.1 to $2.8 \mathrm{mg} / \mathrm{L}$, with a mean of $1.08 \pm \mathrm{SD}$ $0.64 \mathrm{mg} / \mathrm{L}$. Nitrate levels in the area of study did not exceed the standard set by the health authorities $(<10 \mathrm{mg} / \mathrm{L})$ and there was no significant risk of nitrate contamination in ground water (where $\mathrm{HI}<1$ ).

Conclusion: Residents in Mukim Salor, Kelantan, Malaysia, were exposed to low levels of nitrate in groundwater.

Keywords: Agriculture, nitrate, groundwater, methemoglobinaemia, health risk assessment, Mukim Salor.

\section{Correspondence:}

Shaharudin. Department of Environmental and Occupational Health, Faculty of Medicine and Health Sciences, Universiti Putra Malaysia, 4340o UPM Serdang, Selangor, Malaysia. Email: shaha@upm.edu.my. 